\title{
Analysis of lead, arsenic, and cadmium concentrations in instant noodles within the Canadian market
}

Disha Katyal ${ }^{1}$, Dale Chen ${ }^{2}, \mathrm{Hsin}_{\mathrm{Kuo}}^{3}$

1 Lead Author, B. Tech Student, School of Health Sciences, British Columbia Institute of Technology, 3700 Willingdon Ave, Burnaby BC, V6G 3H2

2 Supervisor, School of Health Sciences, British Columbia Institute of Technology, 3700 Willingdon Ave, Burnaby $\mathrm{BC}, \mathrm{V} 6 \mathrm{G} 3 \mathrm{H} 2$

3 Laboratory Supervisor, School of Health Sciences, British Columbia Institute of Technology, 3700 Willingdon Ave, Burnaby BC, V6G $3 \mathrm{H} 2$

\begin{abstract}
Background: High levels of lead (Pb), arsenic (As), and cadmium ( $\mathrm{Cd}$ ) in instant noodles have been reported in many countries, leading to temporary bans of several popular brands across the globe. There have been no studies analyzing the heavy metal contamination of instant noodles available in Canada to assess the risk for Canadians. As these contaminants are ubiquitous in the environment, they can easily make their way into food products. A diet high in $\mathrm{Pb}, \mathrm{As}$, and $\mathrm{Cd}$ can cause permanent health conditions and death, as these metals are highly toxic even in small amounts and cannot be metabolized by the body.
\end{abstract}

Methods: 30 packets of instant noodles were purchased from 6 different brands available in large popular grocery stores. Individual packs of noodles, and the accompanying dry seasoning packs, were ground using a blender and stored in sterile Ziplock bags. The samples were processed using an acid digest and then analyzed using ICP-MS/MS. Concentrations of lead, arsenic, and cadmium were measured for a comparison with FDA and FAO recommended levels, a cross comparison between wheat and rice noodles, and across all 6 brands.

Results: The results show that the levels of $\mathrm{Pb}, \mathrm{As}$, and $\mathrm{Cd}$ found in instant noodles do not exceed the maximum allowable limits set forth by the FDA and FAO. A significant difference between rice and wheat noodles is noted for $\mathrm{As}$ and $\mathrm{Pb}$ concentrations, where rice $>$ wheat $(\mathrm{p}<0.05)$. A significant difference between brands is also noted for all three heavy metals $(p<0.05)$.

Conclusion: Although the results did not find $\mathrm{Pb}, \mathrm{As}$, and $\mathrm{Cd}$ concentrations to exceed the recommended levels, the results of this study are inconclusive due to the low power of the analyses. It has been established that rice noodles contain overall higher levels of $\mathrm{Pb}$ and As than their wheat counterparts, and the levels vary significantly between different brands. The results indicate a wide window of variability of exposure for Canadians and the low power of the study indicates a larger need for further studies to confirm the findings.

Keywords: instant noodles, heavy metals, lead, arsenic, cadmium, toxic, contamination, ICP/MS-MS, noodles, wheat, rice, Indomie Mi Goreng, Maggi, Mr. Noodles, Pho Chay, Oh! Ricey, Nongshim Mee 


\section{INTRODUCTION}

Consumption of "quick" foods, such as instant noodles, has been steadily growing in popularity worldwide. The convenience and ease of preparation, longer shelf-life, low costs, and the availability of variety of flavours make them a favourite consumer product, especially amongst the younger generation (Gulia, Dhaka \& Khatkar, 2014). However, with the industry's growing demand, there is also increasing awareness about the long-term health effects of such processed foods. Several recent studies conducted in Iran, Nigeria, Bangladesh, and China have found significantly high concentrations of heavy metals in many of the commercially available instant noodle products (Tajdar-Oranj et al., 2018; Charles, Ogbolosingha \& Afia, 2017; Jothi \& Uddin, 2014; Onyema et al., 2014).

Researching heavy metals from a food safety point of view is an important part of protecting public health, especially in the Canadian market where there is a huge demand for ethnic products that are imported from all around the world (FoodExport, 2019). Canadian retailers rely on imported foods to meet the population's demand and these products are monitored by the Canadian Food Inspection Agency (FoodExport, 2019). Lead (Pb) and Cadmium (Cd), for example, are classified as human carcinogen compounds by the International Agency for Research on Cancer (IARC) and should not be consumed even in small amounts (Jothi and Uddin, 2014; Salama \& Radwan, 2005). In addition to cancer, the consumption of foods contaminated with heavy metals can cause illness, disorders, deformation, or deterioration of the heart, brain, liver, kidney, lungs, bone, and spleen.

According to the world instant noodles association, Canada has an annual demand of 190 million units of instant noodles (Global Demand, 2019). Some of the leading shareholders of the industry include: Nestle SA (Switzerland), Ajinomoto Co., Inc. (Japan), The Unilever Group (UK), Campbell
Soup Company (USA), Nissin Foods Co., Ltd (Hong Kong), Capital Foods Ltd. (India), and ITC Ltd. (India). Many of the controversial instant noodle products in previous studies have been associated with these companies -all of which also supply some variety of their products to Canada (Market Watch, 2018).

\section{LITERATURE REVIEW}

\section{Health Significance}

Metals are natural elements with high electrical conductivity, malleability, and luster, which voluntarily lose electrons to form cations (Jaishankar et al., 2014). Heavy metals are metals which have a density of greater than $5 \mathrm{~g} / \mathrm{cm} 3$ and adversely affect the environment and living organisms (Jarup, 2003). Arsenic (As), lead (Pb), and cadmium (Cd) are some of the heavy metals that are omnipresent at low concentrations in soil and in the ground (Andrade, Aschner, and Marreilha Dos Santos, 2017). From there, these metals can bioaccumulate into plants and then reach animals and human tissues through several routes such as inhalation, ingestion, and even dermal contact (Clemens \& Ma, 2016). These metals, once inside the body, compete with essential minerals such as calcium, magnesium, or iron for absorption and bind to vital cellular components like structural proteins, enzymes, and nucleic acids, where they interfere with normal functioning. Heavy metals are toxic to living organisms because they are not metabolized by the body and accumulate in soft tissues (Clemens \& Ma, 2016). The buildup of these heavy metals leads to several ailments such as reduction in neuropsychological function and inhibition of biosynthesis of heme, both of which are caused by high levels of lead in the central nervous system and the circulatory system; tubular nephritis dysfunction and slight anemia are caused by Cadmium build up in the kidneys and blood; Cirrhosis, damage to blood 
vessels, and skin lesions can be caused by the buildup of Arsenic (Jan et al., 2015).

According to The Substance Priority List of Agency for Toxic Substances and Disease Registry (ATSDR), which ranks substances based on frequency, toxicity, and potential for human exposure, ranks arsenic (As), lead (Pb), and cadmium (Cd) in the first, second, and seventh positions (ATSDR, 2017).

Although some metals are essential for maintaining various biochemical and physiological functions in living organisms, heavy metals are highly toxic especially when their concentrations exceed certain thresholds (Jaishankar et al., 2014). With increasing pollution around the world, heavy metals have become significant environmental pollutants and their toxicity is a problem of growing significance for ecological, evolutionary, nutritional, and environmental reasons (Jaishankar et al., 2014; Nagajyoti et al., 2010). In terms of susceptibility, long term exposure to heavy metals is lethal to all populations but infants, young children, developing fetus of pregnant women, and those working in occupations with routine exposure are most at risk (Landrigan et al., 2017; “Heavy Metals", 2018).

Health risks associated with exposure to heavy metals can be expressed as Provisional Tolerable Weekly Intake (PWTI), a reference value established by WHO (2009). These guidelines recommend that the weekly intake of lead, cadmium, and arsenic from all sources should not exceed $0.025,0.007$, and 0.015 $\mathrm{mg} / \mathrm{kg}$ body weight, respectively, particularly in children (WHO, 2009). Cadmium, lead, and arsenic are among the most abundant heavy metals and are particularly toxic (Jothi \& Uddin, 2014). Despite the strong evidence against heavy metals, there is insufficient information about the analysis of heavy metals in instant noodles that are available in Canada. Hence, this study aims to meet a void in research. It is important to detect the amount of heavy metals in commercial brands of noodles in order to evaluate the possible risk of their consumption in Canadians. This research study is undertaken to determine the levels of three most common heavy metals: lead (Pb), cadmium (Cd), Arsenic (As), in instant noodles available in the Canadian market.

\section{Exposure}

Arsenic

Arsenic is a prominently toxic and carcinogenic metal (Gordon \& Quastel, 1948). It is ubiquitous, being found in air, water, fuels, and marine life (WHO, 2009). The greatest amount of arsenic in human intake is from fish and crustaceans; in some areas, contaminated groundwater is also a big source (WHO, 2009). Physiologically, arsenic affects the liver, kidney, lungs, spleen, and the intestines (WHO, 2009; Gordon \& Quastel, 1948). Though death with acute arsenic intoxication is rare, chronic exposure can lead to severe irreversible effects caused by neurotoxicity, cardiovascular and renal toxicity, and carcinogenicity (WHO, 2009).

\section{Lead}

Lead, in its elemental form, is a bright silvery metal, which turns slightly bluish in a dry atmosphere (Jaishankar et al., 2014). It is an extremely toxic metal that disturbs various physiological processes. Lead increases the production of reactive oxygen species (ROS) which leads to an imbalance between the production of free radicals and the generation of antioxidants, which would normally repair the damage. Excess ROS leads to lipid membrane disruption that ultimately leads to damage to the cells, proteins, enzymes, nucleic acids (Mathew et al., 2011). Primary mode of exposure to lead is through contaminated food and drinking-water, the use of lead-glazed ceramics for food storage, and ingestion of lead containing paint (WHO, 2009). Each year, in the US, more than 100 to 200000 tons of lead is released from vehicle exhausts alone (Jaishankar et al., 2014). Some is taken up by plants, fixed into soil, and some flows into water bodies -leading to human exposure 
through food or drinking water (Goyer, 1990). The World Health Organization states that there is no level of lead exposure that can be considered safe (Landrigan et al., 2017; "Heavy Metals", 2018). Lead is particularly more dangerous to children because they can absorb it four to five times more effectively than adults, and their brains and nervous systems are more sensitive to the damaging effects (Meyer et al., 2008).

\section{Cadmium}

More than $90 \%$ of human exposure to cadmium is through foods and food products (WHO, 2009). It is commonly found in paints, coatings, pigments, plastics, tobacco smoke, and batteries (WHO, 2009). With increasing plastic pollution around the world, cadmium levels in the soil have increased; it is able to stay stable in soil and sediments for decades until picked up by plants (Jaishankar et al., 2014). Cadmium is predominantly found in fruits and vegetables due to its high rate of soil-to-plant transfer (Satarug et al., 2011). Although the exact mechanism of cadmium toxicity inside the body is not understood, it is known that it results in hepatotoxicity and accumulates in renal tissue causing nephrotoxicity (Patrick, 2003). Cadmium competes with iron inside the body and often leads to iron deficiency (Castagnetto et al., 2002).

\section{Impact on Food}

Since it has been established that heavy metals are naturally present in the environment and pollution is the leading cause of increasing levels of contamination, it is important to study the modernday dietary foods that may be affected. $60 \%$ of the world's food energy comes from grains: rice, maize, and wheat (Staple foods: what do people eat, n.d.). Whether consumed on their own or processed into instant or ready-to-eat foods such as noodles or crackers, the key ingredients are grains. Being one of the main sources of energy and carbohydrates, grains are also prone to be contaminated naturally (Thielecke \& Nugent, 2018). As a food category, they are one of the main dietary sources of foodborne contaminants
(Thielecke \& Nugent, 2018). The contamination of grains is mostly due to air, dust, soil, water, insects, rodents, birds, animals, microbes, transportation and human handling.

The transfer and accumulation of heavy metals from soils to grains and then to humans is of great significance for public health risk assessment and pollution control (Liu et al., 2017). Several analysis studies of wheat grains and farmland soil from different regions of China have shown that both contain levels of $\mathrm{Pb}, \mathrm{As}, \mathrm{Hg}$, and $\mathrm{Cd}$ that exceed the permissible limits of Chinese national standards for food safety (Huang et al., 2008; Liu et al., 2017). Similar studies performed in other regions, such as Saudi Arabia, have yielded similar results; an analysis of rice grains commonly available in the Saudi Arabian market revealed significantly high levels of $\mathrm{As}, \mathrm{Pb}$, and $\mathrm{Hg}$, which exceeded the standards set by Food and Agriculture Organization and the World Health Organization (Al-Saleh \& Abduljabbar, 2017).

A recent study analyzing heavy metal contamination in instant noodles revealed exceeding concentrations of $\mathrm{Pb}$ in products sold in Nigeria, but showed acceptable levels of $\mathrm{As}, \mathrm{Hg}$, and $\mathrm{Cd}$ (Charles, Ogbolosingha, \& Afia, 2017). Another such study, comparing the heavy metal contamination of instant noodles made in Iran to those that were imported into the country, revealed significantly high concentrations of $\mathrm{Pb}, \mathrm{Cd}, \mathrm{Cr}$, and $\mathrm{Al}$ in Iranian samples (Tajdar-Oranj et al., 2018; Onyema et al., 2014).

\section{Manufacturing Process and Contamination}

To better understand the potential sources of contamination of instant noodles, it is important to study their standard manufacturing practices. According to the World Instant Noodles Association (n.d.), the first step in processing is mixing and kneading which involves mixing of wheat or rice flour with water; this process forms dough with the consistency required to give noodles their elasticity. The next steps involve compounding, rolling, and slitting to give noodles their wavy shape. Most instant 
noodles are steamed for $1-5$ minutes at $100 \mathrm{C}$ to pregelatinize the starch and are dipped in seasoning before being molded into their final shape (round cups or square packs). Flash fryers are used to dehydrate the noodles either by oil-frying or air-drying and then are cooled with air. The final product is inspected for weight, shape, color, dryness, and cooling temperature. (World Instant Noodles Association, n.d.).

There are several stages during the manufacturing process of instant noodles which pose a threat of contamination. Some examples include direct contact with metal surfaces during processing, contamination through air pollution during drying processes, and contamination through human contact (Jothi \& Uddin, 2014). In addition to having bioaccumulation of lead, cadmium, and arsenic in raw ingredients, the water used for processing can also pose a threat (Jothi \& Uddin, 2014).

\section{Research Question}

The purpose of this study is to determine whether the instant noodles available in Canada contain $\mathrm{Pb}, \mathrm{As}$, and $\mathrm{Cd}$ in levels exceeding the limits set forth by the US Food and Drug Agency [FDA] and the Food and Agriculture Organization of the United Nations [FAO].

\section{MATERIALS \& METHODS}

\section{Sampling}

Convenience sampling was used in this study to allow for the selection of the most easily accessible instant noodle brands to Canadians (Dudovskiy, n.d.). Thirty samples of readily available instant noodles were purchased from Walmart and T\&T. Five packages of each of the six selected brands were included, while ensuring that fifteen of both wheat and rice varieties were sampled.

Inclusion Criteria: any rice or wheat-based instant noodles within the brands of Indomie Mi Goreng, Maggi, Mr. Noodles, Pho Chay, Oh! Ricey, and
Nongshim Mee with CFIA approved nutrition labels that are available in the Canadian market through Walmart and T\&T.

Exclusion Criteria: any rice or wheat-based instant noodles that are not within the brands of Indomie Mi Goreng, Maggi, Mr. Noodles, Pho Chay, Oh! Ricey, and Nongshim Mee without the CFIA approved nutrition labels that are available in the Canadian market through Walmart and T\&T.

\section{Sample Handling and Preparation}

The Government of Canada, Canadian Food Inspection Agency, \& Food Safety and Consumer Protection Directorate (2019) have guidelines that outline proper procedures for sample handling. Standard methods were used in the pilot study, but additional changes were required for the full project due to limitations in resources and time.

All samples were kept in their original, unopened packaging and aseptic techniques were used for handling. Sterile gloves were used for direct handling and overall air exposure to the samples was minimized. The tabs of the packs were used to open, with minimal contact to the opening of the bag. (Government of Canada et al., 2019).

The Canadian Food Inspection Agency's (CFIA) standard analytical methods for evaluating chemical contamination in feed samples were followed. Dry noodles and their respective dry seasonings were ground using a Magic Bullet Blender and the samples were stored in sterile zip lock bags. The samples were processed following standard acid-digest procedures, using nitric acid and a pressurized microwave. The digested samples were filtered to remove solids and diluted using ultra pure water. The metal analysis was carried out using the ICP-MS/MS, which was calibrated using the internal standards provided by the manufacturer. These methods are a universal standard for analyzing trace metal concentrations in food and drinks and have been used in several similar studies (Al-Saleh \& Abdulijabbar, 2017; Charles, Ogbolosingha \& Afia, 2017; Tajdar-Oranj et al., 2018; Government of Canada, Canadian Food Inspection Agency, 2019). 


\section{Statistical Analysis}

Table 1 outlines the standards set forth by the FDA and FAO for maximum exposure to lead, cadmium, and arsenic in foodstuffs (U.S. Food and Drug Administration, 2020; Codex Alimentarius Commission, 2018). These values were used for comparison with the trace concentrations found in all the thirty samples tested. NCSS 2019 v19.0.3 was used for all statistical analyses (NCSS, 2019).

Table 1: FDA and FAO maximum limits for lead, cadmium, and arsenic exposure via ingestion (U.S.

Food and Drug Administration, 2020; Codex Alimentarius Commission, 2018).

\begin{tabular}{|c|c|c|}
\hline \multicolumn{3}{|c|}{$\mathrm{mg} / \mathrm{kg}$} \\
\hline $\mathrm{Pb}$ & $\mathrm{Cd}$ & $\mathrm{As}$ \\
\hline 0.1 & 0.1 & 0.2 \\
\hline
\end{tabular}

First, to determine whether commonly available instant noodles in the Canadian market contain lead, cadmium, and arsenic in concentrations greater than the maximum allowable limits, OneSample T-tests were used to compare the mean values of each of the three heavy metal concentrations to their standard values. Next, to determine whether the lead concentrations are significantly different between rice and wheat-based noodles, two-sample t-tests were used to compare the means of the two groups. Finally, to compare the heavy metal concentrations between all six brands, ANOVA tests were used to compare the means of all six groups.

\section{RESULTS}

\section{Descriptive and Inferential Statistics}

One-sample T-tests were used to compare the collected values of $\mathrm{Pb}, \mathrm{As}$, and $\mathrm{Cd}$ from the 30 samples to their corresponding maximum allowable limits, and it was determined that the tested noodles did not violate the guidelines. $\mathrm{H}_{0}$ was not rejected ( $\left.p>0.05\right)$, and it was concluded that the concentrations of $\mathrm{Pb}, \mathrm{As}$, and $\mathrm{Cd}$ were less than or equal to their maximum allowable limits. Figures 1-3 outline $\mathrm{Pb}, \mathrm{As}$, and $\mathrm{Cd}$ concentrations found in all samples and compare them to their maximum allowable limits.

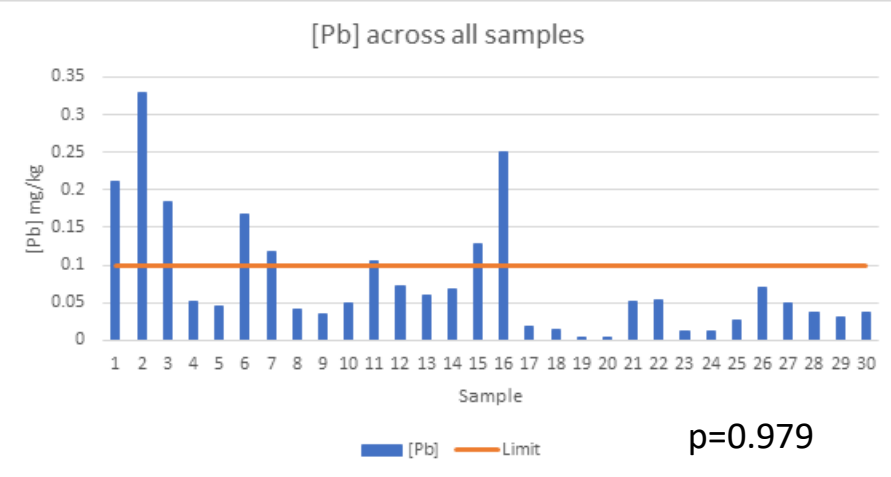

Figure 1

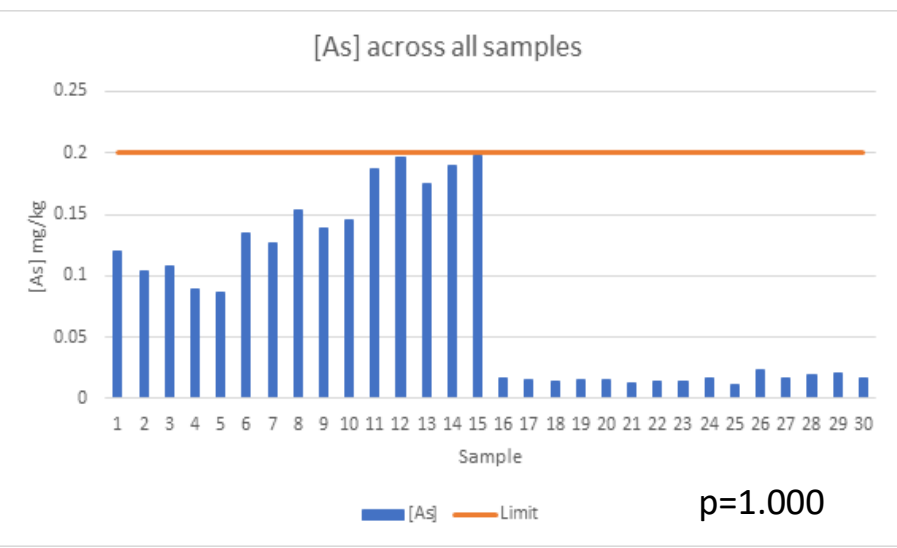

Figure 2

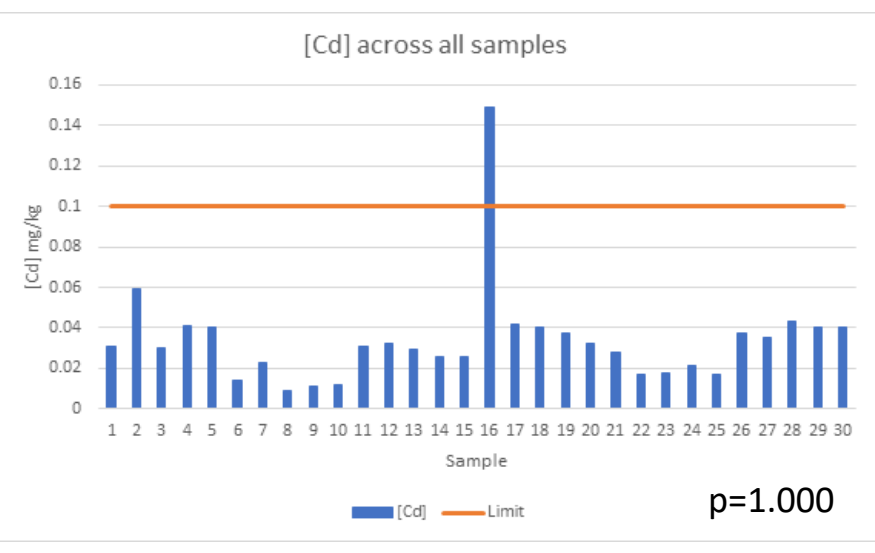


Figure 3

A comparison between wheat and rice-based noodles was carried out using single-tailed independent T-tests which determined that ricenoodles had significantly higher levels of $\mathrm{Pb}$ and $\mathrm{As}$ $(p<0.05)$ than wheat noodles, while Cd levels were the same between the two groups ( $p>0.05$ ). Figures 4-6 show the comparison of wheat and rice noodles.

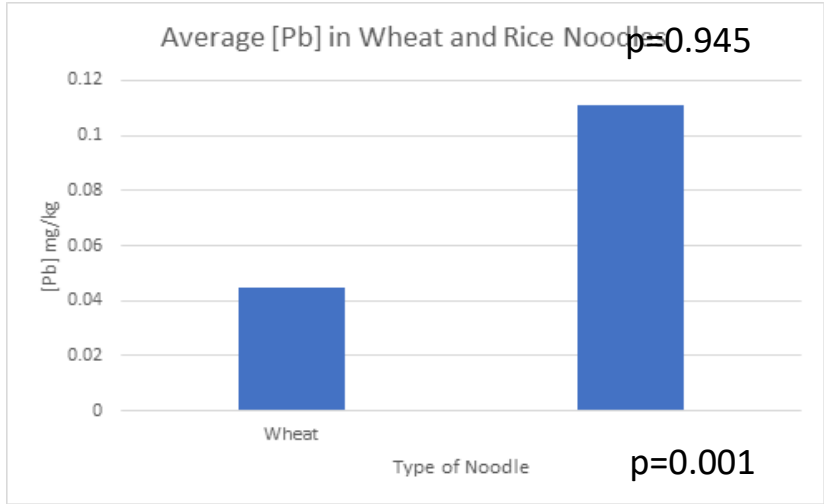

Figure 4

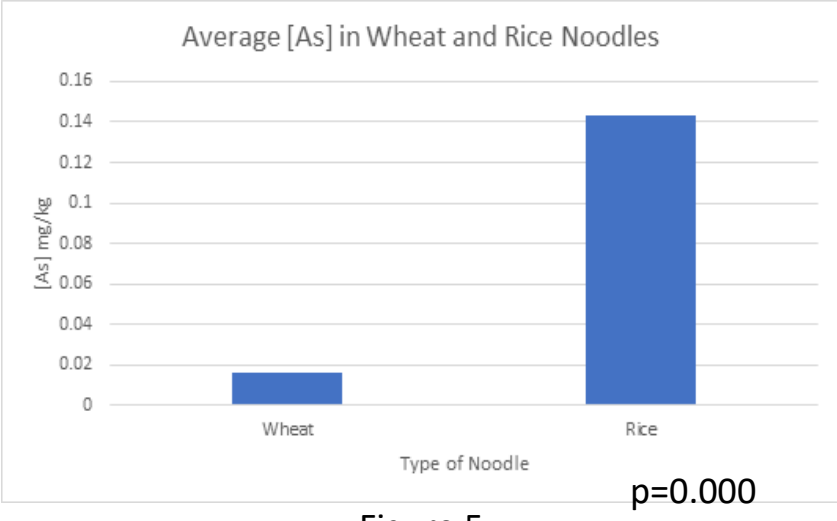

Figure 5

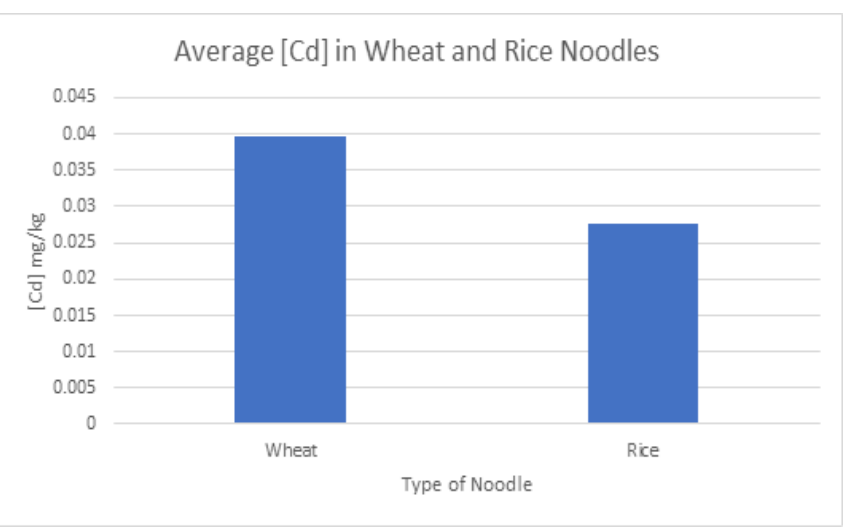

Figure 6

Analysis of individual brands was carried out using one-way ANOVA tests which determined that at least 2 of the 6 brands had significantly different levels of $\mathrm{Pb}, \mathrm{As}$, and $\mathrm{Cd}(\mathrm{p}<0.05)$.

\section{DISCUSSION}

Considering the method validation parameters, the limits of detection (LOD) for $\mathrm{Pb}, \mathrm{As}$, and $\mathrm{Cd}$ were 0.01, 0.002, and $0.004 \mathrm{ug} / \mathrm{kg}$, respectively. The assessment of $\mathrm{Pb}, \mathrm{As}$, and $\mathrm{Cd}$ in instant noodles showed that these metals are present in all samples in varying concentrations. The levels of the three heavy metals were not in violation of the maximum allowable limits set forth by the FDA and FAO ( $p>0.05)$. However, the power of these statistical analyses is low, indicating that the results are inconclusive. Studies with low statistical power increase the likelihood that a statistically significant finding represents a false positive result.

A similar study conducted in Bangladesh reported lead concentrations between 1.17 to 1.67 $\mathrm{mg} / \mathrm{kg}$, which are well above the FDA and FAO maximum allowable level of 0.1 but less than the Bangladesh national standards (Jothi \& Uddin, 2014). The same study found cadmium levels to be in the range of 0.53 to $0.82 \mathrm{mg} / \mathrm{kg}$ which also exceed the maximum allowable limit of 0.1 (Jothi \& Uddin, 2014). In another study which analyzed local and imported instant noodles in the Iranian market found lead levels to be between 0.32 to $2.88 \mathrm{mg} / \mathrm{kg}$ which surpassed the 
WHO maximum level of $0.025 \mathrm{mg} / \mathrm{kg}$ at the time; the same study found cadmium levels to be between 0.03 to $0.35 \mathrm{mg} / \mathrm{kg}$ (Tajdar-Oranj et al., 2018). Another study in Nigeria, testing samples from Port Harcourt, found a wide range of lead levels in instant noodles, from 0.043 to $3.163 \mathrm{mg} / \mathrm{kg}$, the average of which also violated the maximum allowable limits but, found no cadmium and arsenic at all (Charles et al., 2018; Onyema et al., 2014).

Levels of lead found in the present study, ranging between 0.003 to $0.250 \mathrm{mg} / \mathrm{kg}$, are on average less than those found in previous studies from other regions of the world and no violation of the maximum allowable limits is reported. The range of cadmium levels was the same as most previous studies, ranging between 0.009 to $0.149 \mathrm{mg} / \mathrm{kg}$ and did not exceed the maximum value. More research is required to confirm the findings.

The present study found lower levels of $\mathrm{Cd}, \mathrm{Pb}$, and As than most previous studies from around the world, likely because of the stringent import laws enforced by the Canadian Food Inspection Agency that protect food quality for Canadians. The CFIA continuously monitors food quality of products getting imported from around the world and hold companies accountable for the quality of their products. Though not every item is tested for contamination, randomized samples are monitored, and manufacturers are required to provide certified lab reports for quality assurance. The presence of such laws reduces the likelihood of Canadians getting exposed to contaminated food products. (Government of Canada, Canadian Food Inspection Agency, 2019).

A comparison of heavy metal concentrations between wheat and rice noodles revealed that the rice noodles contained higher levels of $\mathrm{Pb}$ and $\mathrm{As}$, as compared to wheat noodles $(p<0.05)$. The power of the analyses was $79 \%$ and $100 \%$, respectively for lead and arsenic. This is in line with previous studies which have shown higher levels of heavy metals, particularly arsenic, in rice-based products, when compared to wheat or other grains (Su, Mcgrath, \& Zhao, 2010). On the other hand, $\mathrm{Cd}$ levels were not significantly different between the two varieties but had a very low power of $0.1 \%$, indicating the presence of a type II error. Type II errors are caused by a small sample size or insufficient data, and their presence can deem the result as inconclusive because there is not enough data in the study to confidently confirm the findings.

Rice noodles have been found to contain higher concentrations of heavy metals as compared to wheat noodles because rice crops require a lot more water for irrigation than wheat crops, which causes heavy metals to accumulate in the grains in larger amounts (Thielecke \& Nugent, 2018; Kong et al., 2018). Arsenic, particularly, is absorbed at a much larger scale than other heavy metals during rice cultivation due to its natural properties (Thielecke \& Nugent, 2018). Bioaccumulation of heavy metals in crops is dependent on soil properties, bioavailability of heavy metals during crop cultivation, pollution levels, water quality, and mining practices (Kong et al., 2018). Thus, good agricultural practices and good manufacturing processes, to monitor and control water and soil quality during crop cultivation, can protect the public from consuming dangerously high levels of $\mathrm{As}, \mathrm{Pb}$, and Cd (Thielecke \& Nugent, 2018; Kong et al., 2018).

A cross comparison of all six brands revealed that there is significant variation in $\mathrm{Pb}, \mathrm{As}$, and $\mathrm{Cd}$ levels between brands $(p<0.05)$. This implies that the consumption of specific brands over others can have a large impact on overall exposure. However, due to the low power of the study, specific differences between individual brands could not be calculated.

Although the results of this study do not refute the null hypotheses and deem the instant noodles safe in terms of heavy metal contamination, the low power of the statistical analyses raises a flag of concern due to a high possibility of false negative results. When looking at individual samples for their heavy metal contamination or comparing the range of levels, as seen in Figures 1-3, it is evident that many instant noodles exceed the maximum allowable limits and can pose a threat to human health if consumed regularly. A larger study is required to obtain a stronger result 
which can confidently claim the safety of these products.

In terms of direct consumer risk, the values reported in this study are applicable to dry noodles only. It has been previously determined that the risk of heavy metals in plain noodles can be significantly reduced if they are consumed after boiling for 3 minutes and if the water used for boiling is removed (Lee et al., 2019). There have been no studies comparing the concentration of heavy metals in dry and cooked instant noodles particularly, but the findings of plain noodles can be used for reasonable predictions. However, plain noodle cooking processes are not directly applicable to instant noodles as they take away from their key properties, which include convenience and cooking efficiency. Draining or excessively boiling instant noodles affects the quality of the product and causes changes in texture or flavours, which may affect consumer behavior. Therefore, since instant noodles are boiled to some extent, though not drained, the level of heavy metals may not differ from those found in dry noodles. Further studies should explore the differences in contamination before and after cooking of instant noodles to better understand the risk to public health.

\section{LIMITATIONS}

Some limitations of this study include time and monetary restrictions, availability of laboratory equipment, and accessibility of recent consumer reports. A longer time period and a larger budget for this study would have allowed for a larger sample size to be tested. A larger sample size would have resulted in a stronger study by improving the external validity of the test allowing the results to be directly applicable to the general population. A larger budget would have also allowed for the accessibility of recent business reports which would have provided insight about popular purchasing behaviors of the Canadian population in terms of specific instant noodle brands. This information would have improved the sample selection process and would have resulted in a more targeted test, improving the internal validity of the study. The relationship between heavy metals exposure and consumption of instant noodles would better implicate the public health significance if samples that best represent exposure to the general public were selected, and not just by convenience.

\section{KNOWLEDGE TRANSLATION}

With research studies from around the world detecting high levels of heavy metal contamination in grains and grain-based products, it is important for Canadians to be wary of the foods they purchase and consume. Public health initiatives should be introduced to educate the public of risks involved with the consumption of instant noodles and ways of reducing their exposure. Some studies have shown that pre-soaking the rice or grain-product prior to cooking reduces heavy metal concentration (Al-Saleh \& Abduljabbar, 2017) along with boiling and draining the noodles (Lee et al., 2019) -such cooking behaviours can be promoted to reduce public risk.

Health Canada should produce a code of practice for the prevention and reduction of heavy metal contamination in food. As heavy metal contaminants are naturally occurring, it is not possible to impose total bans on their presence in food items. The most competent response to control their levels is by establishing and enforcing maximum allowable limits that are technologically possible for testing. Strict guidelines should be put in place to create a standard for food safety for Canadian consumers. Presently, there are no set limits for $\mathrm{Pb}, \mathrm{As}$, and $\mathrm{Cd}$ in instant noodles or similar products that are enforced by the Canadian authorities, which increases reliability on levels set forth by the FDA in the United States or other authorities. The World Health Organization in the past used to have guidelines and global recommended levels which were recently retracted, making the comparison difficult for food products (WHO, 2019). The FDA has Pb limits for baby food and candy, which were used in this study -but no specific levels exist for grain products intended for human 
consumption (U.S. Food and Drug Administration, 2020).

Further research should be conducted to confirm the findings of this study so better education, new policies and legislation can be implemented to equip the public with greater knowledge and awareness about the impact of heavy metals on their health.

\section{FUTURE RESEARCH}

Future studies should explore the following:

- A larger sample size of rice-based noodles

- Differences in heavy metal contamination of raw and cooked instant noodles

- Heavy metal contamination of pasta, spaghetti, and other related wheat products

- Heavy metal contamination of ready-to-eat snacks with similar ingredients as to instant noodles (Doritos, Crunchy Cheetos, etc.)

\section{CONCLUSION}

\section{REFERENCES}

Agency for toxic substances and disease registry [ATSDR]. (2017). The priority list of hazardous substances that will be the subject of toxicological profiles. Retrieved October 16, 2019: https://www.atsdr.cdc.gov/SPL/

Al-Saleh, I., \& Abduljabbar, M. (2017). Heavy metals (lead, cadmium, methylmercury, arsenic) in commonly imported rice grains ( Oryza sativa ) sold in Saudi Arabia and their potential health risk. International Journal of Hygiene
This study is the first of its kind to compare heavy metal concentrations in instant noodles available in the Canadian market to the maximum allowable values reported by the FDA and FAO. Due to the limitations of the study, the results were inconclusive. However, a significant difference in heavy metal contamination was noted between rice and wheat noodles; rice-based noodles were shown to have higher levels of $\mathrm{Pb}, \mathrm{As}$, and $\mathrm{Cd}$. It was also determined that the levels of heavy metals were significantly different between brands, which indicates a wide window of variability of exposure for the public. The unclear results indicate a larger need for research so the severity of contamination of instant noodles can be better understood. Past research has shown that heavy metal levels can be reduced significantly by changing cooking procedures. Canadians should be educated about these practices so cultural changes can occur and the overall risk of heavy metal exposure can be reduced. It is also strongly recommended that the regulatory agencies of Canada, such as Health Canada and CFIA, establish strict standards for maximum allowable levels for heavy metals in all consumables to better control food quality in Canada.

\section{COMPETING INTEREST}

The authors declare that they have no competing interests. 
Institute. Nucleic acids research, 30(1), 379382. doi:10.1093/nar/30.1.379

Charles, I. A., Ogbolosingha, A. J., \& Afia, I. U. (2017). Health risk assessment of instant noodles commonly consumed in Port Harcourt, Nigeria. Environmental Science and Pollution Research, 25(3), 2580-2587. doi: 10.1007/s11356-017-0583-0

Clemens, S., \& Ma, J. F. (2016). Toxic Heavy Metal and Metalloid Accumulation in Crop Plants and Foods. Annual Review of Plant Biology, 67(1), 489-512. doi: 10.1146/annurevarplant-043015-112301

Codex Alimentarius Commission. (2018). Joint Food and Agriculture Organization of the United Nations and World Health Organization Food Standards Programme Codex Committee on Contaminants in Foods. Retrieved November 18, 2019, from http://www.fao.org/fao-whocodexalimentarius/shproxy/en/?!nk=1\&url=https\%253A\%252F\%25 2Fworkspace.fao.org\%252Fsites\%252Fcodex \%252FMeetings\%252FCX-73512\%252FWD\%252Fcf12 INF01x.pdf

Dudovskiy, J. (n.d.). Convenience sampling Research Methodology. Retrieved March 15, 2020, from https://researchmethodology.net/sampling-in-primary-datacollection/convenience-sampling/

Food Export. (2019). Canada Country Profile. Retrieved March 17, 2020, from https://www.foodexport.org/import-usproducts/get-started/country-marketprofiles/north-america/canada-countryprofile

Global Demand. (2019). Retrieved September 25, 2019, from https://instantnoodles.org/en/noodles/mark et.html.
Gordon, J. J., \& Quastel, J. H. (1948). Effects of organic arsenicals on enzyme systems. Biochemical Journal, 42(3), 337-350. doi: 10.1042/bj0420337

Government of Canada, Canadian Food Inspection Agency, \& Food Safety and Consumer Protection Directorate. (2019, November 1). Sampling procedures. Retrieved from https://www.inspection.gc.ca/food/requirem ents-and-guidance/preventive-controls-foodbusinesses/samplingprocedures/eng/1518033335104/152820340 3149.

Government of Canada, Canadian Food Inspection Agency. (2019). Analytical methods for the determination of nutrients, inorganic and organic compounds and contaminants, and biological contaminants in livestock feeds. Retrieved November 17, 2019, from https://www.inspection.gc.ca/animals/feeds/ inspection-program/analytical-methods-forthe-determination-ofnutrie/eng/1566313727551/1566313883254.

Goyer, R. A. (1990). Lead Toxicity: From Overt to Subclinical to Subtle Health Effects. Environmental Health Perspectives, 86, 177. doi: $10.2307 / 3430951$

Gulia, N., Dhaka, V., \& Khatkar, B. S. (2014). Instant Noodles: Processing, Quality, and Nutritional Aspects. Critical Reviews in Food Science and Nutrition, 54(10), 1386-1399. doi: 10.1080/10408398.2011.638227

Han, J. X., Shang, Q., Du, Y. (2009). Effect of environmental cadmium pollution on human health. Health, 1(3), 159-166.

Heavy Metals. (2018). Retrieved October 16, 2019, from https://epi.envirocenter.yale.edu/2018epi-report/heavy-metals.

Huang, M., Zhou, S., Sun, B., \& Zhao, Q. (2008). Heavy metals in wheat grain: Assessment of 
potential health risk for inhabitants in

Kunshan, China. Science of The Total

Environment, 405(1-3), 54-61. doi:

10.1016/j.scitotenv.2008.07.004

Jaishankar, M., Tseten, T., Anbalagan, N., Mathew,

B. B., \& Beeregowda, K. N. (2014). Toxicity, mechanism and health effects of some heavy metals. Interdisciplinary toxicology, 7(2), 6072. doi:10.2478/intox-2014-0009

Jan, A. T., Azam, M., Siddiqui, K., Ali, A., Choi, I., \& Haq, Q. M. (2015). Heavy Metals and Human Health: Mechanistic Insight into Toxicity and Counter Defense System of Antioxidants. International journal of molecular sciences, 16(12), 29592-29630. https://doi.org/10.3390/ijms161226183

Järup, L. (2003). Hazards of heavy metal contamination. Br Med Bull, 68(1), 167-182.

Jothi, J. S., \& Uddin, M. B. (2014). Detection of heavy metals in some commercial brands of noodles. European Academic Research, 2(8), 10667-10679

Katyal, D., Chen, D., \& Kuo, H. (2020). Analysis of lead, arsenic, and cadmium concentrations in instant noodles within the Canadian market. BCIT Institutional Repository Environmental Health Journal.

Kong, X., Liu, T., Yu, Z., Chen, Z., Lei, D., Wang, Z., Zhang, H., Li, Q., \& Zhang, S. (2018). Heavy Metal Bioaccumulation in Rice from a High Geological Background Area in Guizhou Province, China. International journal of environmental research and public health, 15(10), 2281.

https://doi.org/10.3390/ijerph15102281

Landrigan, P. J., Fuller, R., Acosta, N. J. R., Adeyi, O., Arnold, R., Basu, N. (Nil), ... Zhong, M. (2017). The Lancet Commission on pollution and health. The Lancet.
https://doi.org/10.1016/S0140-

6736(17)32345-0

Lee, J.-G., Hwang, J.-Y., Lee, H.-E., Kim, T.-H., Choi, J.-D., \& Gang, G.-J. (2019). Effects of food processing methods on migration of heavy metals to food. Applied Biological Chemistry, 62(1). doi: 10.1186/s13765-0190470-0

Liu, B., Ai, S., Zhang, W., Huang, D., \& Zhang, Y. (2017). Assessment of the bioavailability, bioaccessibility and transfer of heavy metals in the soil-grain-human systems near a mining and smelting area in NW China. Science of The Total Environment, 609, 822829. doi: 10.1016/j.scitotenv.2017.07.215

Market Watch. (2018, November 14). Instant Noodles Market 2018 Global Share, Trend, Segmentation and Forecast to 2023.

Retrieved from https://www.marketwatch.com/pressrelease/instant-noodles-market-2018-globalsharetrendsegmentation-and-forecast-to2023-2018-11-14.

Mathew, B. B., Tiwari, A., Jatawa, S. K. (2011). Free radicals and antioxidants: A review. Journal of Pharmacy Research, 4(12), 4340-4343.

Meyer, P. A., Brown, M. J., \& Falk, H. (2008). Global approach to reducing lead exposure and poisoning. Proceedings of the 5th International Conference on Environmental Mutagens in Human Populations (ICEMHP), 659(1), 166-175. https://doi.org/10.1016/j.mrrev.2008.03.003

Nagajyoti, P. C., Lee, K. D., \& Sreekanth, T. V. M. (2010). Heavy metals, occurrence and toxicity for plants: a review. Environmental Chemistry Letters, 8(3), 199-216. doi: 10.1007/s10311010-0297-8

NCSS: Statistical \& Power Analysis Software (2019). NCSS, LLC. Kaysville, Utah, USA, ncss.com/software/ncss. 
Onyema, C. T., Ekpunobi, U. E., Edowube, A. A., Odinma, S., \& Sokwaibe, C. E. (2014). Quality Assessment of Common Instant Noodles Sold in Nigeria Markets. American Journal of Analytical Chemistry, 05(17), 1174-1177. doi: 10.4236/ajac.2014.517124

Patrick, L. (2003). Toxic metals and antioxidants: Part II. The role of antioxidants in arsenic and cadmium toxicity. Altern Med Rev, 8(2), 106128.

Salama, A., \& Radwan, M. (2005). Heavy metals (Cd, $\mathrm{Pb})$ and trace elements ( $\mathrm{Cu}, \mathrm{Zn}$ ) contents in some foodstuffs from the Egyptian market. Emirates Journal of Food and Agriculture, 17(1), 34. doi: 10.9755/ejfa.v12i1.5046

Satarug, S., Garrett, S. H., Sens, M. A., \& Sens, D. A. (2011). Cadmium, environmental exposure, and health outcomes. Ciencia \& saude coletiva, 16(5), 2587-2602. doi:10.1590/s1413-81232011000500029

Staple foods: What do people eat? (n.d.). Retrieved October 16, 2019, from http://www.fao.org/3/u8480e/u8480e07.ht $\mathrm{m}$.

Su, Y., Mcgrath, S. P., \& Zhao, F. (2010). Rice is more efficient in arsenite uptake and translocation than wheat and barley. Plant and Soil, 328(12), 27-34. doi:http://dx.doi.org/10.1007/s11104-0090074-2

Tajdar-Oranj, B., Shariatifar, N., Alimohammadi, M., Peivasteh-Roudsari, L., Khaniki, G. J., Fakhri, Y., \& Khaneghah, A. M. (2018). The concentration of heavy metals in noodle samples from Iran's market: probabilistic health risk assessment. Environmental Science and Pollution Research, 25(31), 30928-30937. doi: 10.1007/s11356-018$3030-y$
Thielecke, F., \& Nugent, A. (2018). Contaminants in Grain-A Major Risk for Whole Grain Safety? Nutrients, 10(9), 1213. doi:

10.3390/nu10091213

U.S. Food and Drug Administration[FDA]. (2020, February 27). Lead in Food, Foodwares, and Dietary Supplements. Retrieved March 15, 2020, from https://www.fda.gov/food/metals-and-yourfood/lead-food-foodwares-and-dietarysupplements

World Health Organization [WHO]. (2009). Exposure of Children to Chemical Hazards in Food. Retrieved November 19, 2019, from http://www.euro.who.int/_data/assets/pdf _file/0004/97042/4.4.-Exposure-of-childrento-chemical-hazards-in-foodEDITED_layouted.pdf

World Health Organization [WHO]. (2019). Exposure to lead: a major public health concern. Retrieved December 13, 2019, from https://apps.who.int/iris/bitstream/handle/1 0665/329953/WHO-CED-PHE-EPE-19.4.7eng.pdf?ua $=1$

World Instant Noodle Association. (n.d.). The manufacturing process of instant noodles. Retrieved November 19, 2019, from https://instantnoodles.org/en/noodles/proce ss.html. 